\title{
Avaliação da percepção de crianças e seus responsáveis em relação ao uso de diferentes materiais utilizados para procedimentos restauradores em odontopediatria
}

\author{
Evaluation of the perception of children and their guardians regarding the use of different \\ materials used for restorative procedures in pediatric dentistry \\ Evaluación de la percepción de los niños y sus tutores sobre el uso de diferentes materiales \\ utilizados para procedimientos restaurativos en odontopediatría
}

Recebido: 10/11/2021 | Revisado: 17/11/2021 | Aceito: 21/11/2021 | Publicado: 02/12/2021

\author{
Jaíne Joice Amorim \\ ORCID: https://orcid.org/0000-0002-9582-8403 \\ Centro Universitário de Patos de Minas, Brasil \\ E-mail: jaineamorim@unipam.edu.br \\ Isadora Caroline Tameirão Gomes \\ ORCID: https://orcid.org/0000-0001-6897-1354 \\ Centro Universitário de Patos de Minas, Brasil \\ E-mail: isadoratameirao@unipam.edu.br \\ Lorena Teixeira Melo Bomfim \\ ORCID: https://orcid.org/0000-0002-9998-6046 \\ Cirurgiã dentista, Patos de Minas, Brasil \\ E-mail: lorenatmelob@gmail.com \\ Ludiele Gonçalves Martins Larquer \\ ORCID: https://orcid.org/0000-0002-3967-4649 \\ Cirurgiã dentista, Patos de Minas, Brasil \\ E-mail: ludiele@hotmail.com \\ Denise de Souza Matos \\ ORCID: https://orcid.org/0000-0001-6750-6215 \\ Centro Universitário de Patos de Minas, Brasil \\ E-mail: denisesm@unipam.edu.br
}

\begin{abstract}
Resumo
Introdução: Dentre os materiais restauradores utilizados em odontopediatria, destacam-se o amálgama, a resina composta e mais recentemente os compômeros coloridos, sendo o último bastante popularizado entre as crianças, devido a sua apresentação em cores como azul, prata, rosa, verde, limão e ouro, o que o torna mais interessante para a realização de tratamentos nesse público se comparado aos materiais tradicionais, que por sua vez são as opções de escolha dos pais. Objetivo: Avaliar a percepção de crianças e seus responsáveis em relação ao uso de diferentes materiais utilizados para procedimentos restauradores em odontopediatria. Material e método: Foram recrutadas crianças e seus respectivos pais ou responsáveis, na clínica de Odontopediatria do Centro Clínico Odontológico Unipam, bem como de consultórios particulares de Odontopediatras de Patos de Minas - MG. Para o desenvolvimento da pesquisa foi aplicado um formulário direcionado tanto às crianças, quanto aos seus pais/responsáveis. Este continha imagens, com opção de escolha do material restaurador preferido e um espaço para justificativa da sua preferência. Resultados e Conclusão: Os resultados dessa pesquisa evidenciam que o fator determinante para a escolha dos pais frente a um material restaurador é a estética, sendo o amálgama de prata rejeitado por $100 \%$ e a resina composta na cor natural dos dentes a opção de escolha da maioria dos pais/responsáveis entrevistados. Já as crianças possuem uma visão distinta sobre o que é "feio" ou "bonito" em especial àquelas em idade entre 4 e 7 anos de idade, que optaram maioritariamente pelos compômeros coloridos.
\end{abstract}

Palavras-chave: Estética Dentária; Materiais Dentários; Odontopediatria.

\begin{abstract}
Introduction: Among the restorative materials used in pediatric dentistry, amalgam, composite resin and more recently colored compomers stand out, the latter being quite popular among children, due to its presentation in colors such as blue, silver, pink, green, lemon and gold, which makes it more interesting to carry out treatments in this audience if compared to traditional methods, which in turn are the options of choice for parents. Objective: To evaluate the perception of children and their guardians regarding the use of different materials used for restorative procedures in pediatric dentistry. Material and method: Children and their respective parents or guardians were recruited from the Pediatric Dentistry clinic of the Centro Clínico Odontológico-Unipam, as well as from the private offices of Pediatric Dentists in Patos de Minas-MG. For the development of the research, a form aimed at both children and their
\end{abstract}


parents/guardians was applied. This contained images, with the option to choose the preferred restorative material and a space to justify your preference. Results and Conclusion: The results of this research show that the determining factor for parents' choice of restorative material is esthetics, with silver amalgam rejected by $100 \%$ and composite resin in the natural color of the teeth being the option for the majority. Children, on the other hand, have a different view of what is "ugly" or "beautiful", especially those aged between 4 and 7 years old, who mostly opted for colored compomers.

Keywords: Esthetics Dental; Dental materials; Pediatric dentistry.

\section{Resumen}

Introducción: Entre los materiales restauradores utilizados en odontopediatría destacan las amalgamas, resinas compuestas y más recientemente compómeros coloreados, siendo estos últimos bastante populares entre los niños, por su presentación en colores como azul, plata, rosa, verde, limón y dorado. , lo que hace más interesante la realización de tratamientos en este público si se compara con los materiales tradicionales, que a su vez son las opciones de elección de los padres. Objetivo: Evaluar la percepción de los niños y sus tutores sobre el uso de diferentes materiales utilizados para procedimientos restaurativos en odontopediatría. Material y método: Los niños y sus respectivos padres o tutores fueron reclutados de la clínica de Odontopediatría del Centro Clínico Odontológico - Unipam, así como de los consultorios privados de Odontopediatra en Patos de Minas - MG. Para el desarrollo de la investigación se aplicó un formulario dirigido tanto a los niños como a sus padres / tutores. Este contenía imágenes, con la opción de elegir el material de restauración preferido y un espacio para justificar su preferencia. Resultados y Conclusión: Los resultados de esta investigación muestran que el factor determinante para la elección del material restaurador por parte de los padres es la estética, siendo la amalgama de plata rechazada al 100\% y la resina compuesta en el color natural de los dientes siendo la opción de elección. / tutores entrevistados. Los niños, en cambio, tienen una visión diferente de lo que es "feo" o "bello", especialmente los de entre 4 y 7 años, que en su mayoría optaron por los compómeros de colores.

Palabras clave: Estética dental; Materiales dentales; Odontología pediatrica.

\section{Introdução}

A cárie dentária é uma doença multifatorial, infecciosa e dieta dependente que acompanha a humanidade desde tempos remotos (Lima, 2007). Esta ainda se configura como um dos principais problemas de saúde bucal, afetando cerca de 60 a $90 \%$ das crianças em idade escolar, além de um grande número de adultos (Hugar et al., 2017).

Comumente, os métodos utilizados para abordar as lesões de cárie incluem os tratamentos não invasivos, microinvasivos e invasivos. No entanto, o tratamento invasivo continua sendo o método mais utilizado para tratar a cárie dentária, envolvendo o uso de brocas rotativas e instrumentos manuais para remoção da dentina cariada e em seguida, preenchimento da cavidade com um material restaurador (Dorri, Dunne, Walsh \& Schwendicke, 2015).

No que se refere aos materiais restauradores, a literatura apresenta uma ampla variedade, mas segundo Berg (1998) e F.C.P. Santos, S.C.P. Santos, Souza, Paiva e Marangoni (2020), os indicados para restaurações de lesões cariosas cavitadas são aqueles que, dentre várias propriedades necessárias, possuem boa resistência mecânica à mastigação, custo benefício favorável e, de preferência e se possível, os que proporcionem remineralização por meio do flúor. Desse modo, alguns dos materiais restauradores mais utilizados em odontopediatria são amálgama, cimento de ionômero de vidro, resina composta e os compômeros (American Academy Of Pediatric Dentistry, 2020).

“O amálgama de prata tem sido utilizado como restaurador dentário desde 1880” (Hebling, Araújo \& Myaki, 2017, p.177). Tal material apresenta, dentre as inúmeras propriedades, certas desvantagens que muitas vezes contraindicam seu uso, destacando-se: necessidade de desgaste excessivo da estrutura dental sadia para a sua correta adaptação; toxicidade devido ao mercúrio presente na sua composição e, principalmente, no quesito estética este se apresenta como desagradável para muitas pessoas. Tais características provocaram seu desuso na última década e, em função disso, tornou-se elevada a procura por materiais alternativos mais atraentes e com propriedades capazes de mimetizar a cor do dente (Rosa, 2018).

Com base nessas perspectivas, Bowen (1962), desenvolveu as resinas compostas ou fotopolimerizáveis, que hoje são consideradas "um dos mais elucidativos progressos para a odontologia contemporânea" (Aguiar, 2014, p.1). Haja vista que as características mecânicas, funcionais e estéticas deste material tenham melhorado significativamente, o mesmo tem sido cada 
vez mais utilizado em restaurações dentais diretas na clínica infantil (Piva, Ribeiro \& Coelho-De-Souza, 2014). De certo modo, o uso das resinas compostas foi intensificado após o surgimento dos materiais adesivos, pois em virtude de sua contribuição, preparos cavitários que, a princípio, eram realizados de maneira padronizada com dimensões desnecessariamente grandes, passaram a ser substituídos por procedimentos restauradores menos invasivos (Arinelli, Pereira, Prado \& Rabello, 2016).

Quanto ao quesito estética, as resinas compostas apresentam excelente capacidade de mimetizar a cor da restauração ao dente. Assim, sendo associada à correta técnica restauradora, como a de estratificação, garante propriedades ópticas desejáveis (Correia, Oliveira \& Silva, 2005). Tais propriedades são de grande relevância para a seleção de cor da resina em cada paciente, visto que possibilitam a escolha de diferentes tonalidades de acordo com as pigmentações dos elementos dentais de cada indivíduo, gerando uma harmonia do sorriso e da face (Silva, 2015).

Além das resinas compostas fotopolimerizáveis, foram introduzidos no mercado os compômeros (associação de compósito e ionômero) que, além de estético, é um material de fácil uso, com boas propriedades físicas e apto a liberar flúor (Moreno, Ribeiro \& Melo, 2000), porém, são inferiores às resinas compostas quando se refere à dureza e desgaste superficial (Bussadori, Imparato \& Guedes-Pinto, 2000). A popularização destes materiais, principalmente em Odontopediatria, ocorre devido à sua apresentação em cores, como azul, prata, rosa, verde, limão e ouro, o que o torna mais interessante para a realização de tratamentos em crianças se comparado ao tradicional sistema de sombreamento das resinas (Khodadadi, Khafri \& Aziznezhad, 2016).

No que diz respeito à "aceitação pelos pais de qualquer nova técnica ou material restaurador, a estética é a preocupação primordial" (Crystal, Janal, Hamilton, \& Niederman, 2017, p.511), pois eles a veem como um padrão para se enquadrar dentro das normas aceitáveis na sociedade. Logo, do ponto de vista adulto, a coloração dental é considerada estética quando se trata de dentes "brancos". No entanto, devido à subjetividade, este conceito pode ser diferente no que se refere à visão infantil, principalmente quando envolve crianças em idade pré-escolar, visto que elas possuem visões distintas sobre o que é "feio" ou "bonito" (Furtado et al., 2012).

Logo, considerando-se as apreensões profundas da criança e a dificuldade em realizar atendimento odontológico nos pacientes infantis, e haja vista o pressuposto de que a percepção estética é algo subjetivo se comparado com diferentes públicos, torna-se necessário avaliar a percepção das crianças e de seus responsáveis quanto aos materiais restauradores utilizados em odontopediatria, visto que, é de suma importância que o dentista pediátrico saiba compreender tais apreensões de seus pacientes e tente superá-las por meio de várias técnicas de condicionamento de comportamento. Deste modo, a nova proposta de utilizar compômeros coloridos configura-se como uma alternativa para tornar o tratamento dentário mais atraente às crianças, obtendo maior colaboração, atenuando o medo e dando a elas a chance de escolher a cor do material restaurador utilizado (Khodadadi et al., 2016).

\section{Metodologia}

\subsection{Aspectos Éticos}

Este trabalho foi submetido e aprovado pelo Comitê de Ética em Pesquisa do Centro Universitário de Patos de Minas, CEP - UNIPAM sob o parecer de número 44099121.3.0000.5549. O mesmo obedeceu a legislação nacional vigente para a realização de pesquisa envolvendo seres humanos, conforme a Resolução do Conselho Nacional de Saúde 466/2012.

A coleta de dados iniciou-se apenas após a aprovação do Comitê de Ética, e sob permissão dos voluntários por meio do Termo de Consentimento Livre e Esclarecido-TCLE, e Termo de Assentimento Livre e Esclarecido-TALE, que foram impressos e explicados pelo pesquisador aos participantes individualmente, e os mesmos, cientes da finalidade, objetivo e caráter do estudo, assinaram o termo em caso de interesse em participar da pesquisa. O TALE foi disponibilizado e explicado tanto para as crianças quanto para seus responsáveis e apenas foi assinado após o consentimento dos pais/responsáveis e 
concordância do menor em participar da pesquisa. Participaram da pesquisa apenas aqueles que se interessaram e que assinaram o TCLE e TALE, respeitando a privacidade, sigilo e liberdade de recusa.

\subsection{Amostragem}

A pesquisa foi realizada na clínica de Odontopediatria do Centro Clínico Odontológico do Unipam (CCO) e em consultórios particulares de dentistas odontopediátricos da cidade de Patos de Minas. A amostra, definida por conveniência, envolveu crianças presumivelmente saudáveis, de 4 a 10 anos de idade e seus respectivos pais ou responsáveis. O preenchimento dos questionários foi realizado na sala de espera de ambos os locais selecionados e o número de participantes resultou do nível de aceitação em participar da pesquisa e consequente assinatura do TCLE e TALE. A pesquisa foi realizada até que se obteve um número mínimo de 50 crianças e 50 pais como respondentes compondo a amostra, em cada uma das áreas de coleta de dados, sendo área 1 = CCO e área 2 = consultórios odontológicos particulares da cidade, perfazendo, portanto, um $\mathrm{n}=200$.

\subsection{Delineamento do estudo}

Trata-se de uma pesquisa aplicada, descritiva, de campo, com base em uma abordagem quali-quantitativa. Como fundamentação teórica para orientar a pesquisa, buscou-se por trabalhos publicados nas bases de dados eletrônicas MedlineBireme, Lilacs, Pubmed-NCBI e Scielo assim como por meio de referências citadas nos artigos selecionados (snowballing). Para a pesquisa foram utilizados os seguintes descritores: "Odontopediatria", "Materiais Dentários" e "Estética Dentária" e seus correspondentes em inglês: Pediatric Dentistry, Dental Materials e Dental Aesthetics. Foram selecionados um total de 30 artigos admitidos.

A pesquisa ocorreu em duas etapas, a primeira no Centro Clínico Odontológico-Unipam, que consta com uma população mais carente, Classe C e D. Já a segunda etapa foi realizada em consultórios particulares de dentistas odontopediátricos da cidade de Patos de Minas que apresentam população mais favorecida, classe A e B.

No que se refere à segunda etapa da pesquisa, realizada em consultórios particulares, o número de participantes correspondeu a aproximadamente o mesmo número de participantes obtidos na primeira etapa. As datas selecionadas foram de acordo com a disponibilidade das entrevistadoras, que neste local foram as odontopediatras dos consultórios particulares, que foram calibradas e devidamente capacitadas para realizar as perguntas e o preenchimento dos questionários.

Em ambos os locais selecionados para realização da pesquisa o recrutamento dos pacientes ocorreu na sala de espera da clínica/consultórios de forma individual e neste mesmo local foi realizada a entrevista, onde explicou-se de forma detalhada a cada participante, utilizando o vocabulário adequado, de maneira que tanto os pais quantos as crianças conseguissem compreender o propósito do estudo e assim pudessem optar de forma consciente por participar ou não. Após demostrarem interesse o TCLE e TALE foram lidos e, após a leitura recolheu-se a assinatura dos termos daqueles que consentiram a participação.

Em seguida, realizou-se uma breve explicação sobre o que é a cárie dentária, quando é necessário tratá-la, e o que é uma restauração, sempre utilizando linguagem adequada e simplificada, de modo que os participantes compreendessem o contexto da pesquisa e a importância do tratamento dessas lesões, bem como a necessidade de cuidados com a higiene bucal.

Posteriormente, um formulário de duas sessões foi apresentado aos participantes, a princípio apenas a primeira sessão foi preenchida, que consiste em coleta de dados demográficos, como nome (abreviatura), gênero, idade, número de integrantes/moradores da família e renda familiar. Adiante as crianças foram recrutadas individualmente, longe dos pais, para realizarem a segunda sessão do formulário, que contou com a apresentação de imagens impressas em papel A4 e plastificadas, de um modelo Typodont com várias restaurações presentes, realizadas com materiais dentários do tipo compósito colorido nas 
cores rosa e azul, resina composta e amálgama. As crianças foram questionadas em relação à sua preferida e o motivo da sua escolha. Logo em seguida, o entrevistador devidamente capacitado, assinalou no formulário a imagem correspondente à escolha da criança e relatou no espaço indicado o motivo da escolha com as mesmas palavras usadas pelo respondente.

Por fim, as imagens usadas anteriormente foram apresentadas aos pais/responsáveis e os mesmos foram questionados com relação a qual o seu material preferido para restaurar os dentes da criança ao qual ele é responsável e as razões por trás da sua escolha. Seguidamente, o formulário foi preenchido pelo entrevistador de acordo com as respostas do entrevistado, relatando fielmente as palavras e escolhas do participante.

As imagens contidas no formulário foram selecionadas da internet, tendo como critério de escolha, aquelas que apresentaram alta resolução, ilustraram bem as restaurações com os materiais indicados, e apresentaram restaurações classe I ou II na oclusal de molares, para melhor visualização. Estas foram impressas em folha A4 e plastificadas para facilitar o manuseio e consequente higienização com álcool 70\% após cada utilização.

Em ambos os locais selecionados para realização da pesquisa, seguiu-se todos os protocolos de biossegurança contra a COVID-19, onde o pesquisador/entrevistador esteve devidamente paramentado e seguiu todas as medidas de segurança propostas no protocolo para atendimento no centro clínico Odontológico da FEPAM/UNIPAM durante a pandemia.

\subsection{Critérios de Inclusão}

Crianças com idade entre 4 e 10 anos atendidas pela clínica de odontopediatria do Centro Clínico Odontológico do UNIPAM e de consultórios particulares do município de Patos de Minas; crianças que apresentavam capacidade de compreender os questionários que foram aplicados e seus respectivos pais e responsáveis, aqueles que aceitaram voluntariamente participar da pesquisa e assinaram os termos TCLE e TALE.

\subsection{Critérios de Exclusão}

Foram excluídas as crianças que apresentaram alterações neurológicas, cognitivas e motoras e aquelas que estavam desacompanhadas de pais ou responsáveis legais.

\subsection{Riscos e benefícios}

Este estudo não apresentou nenhum risco significativo de danos à saúde geral dos pacientes, no entanto houve risco moderado de constrangimento ao responder o questionário; estresse, e a quebra de sigilo, que apesar do cuidado com o armazenamento e confidencialidade dos dados, é um possível risco.

Como forma de minimizar esses riscos a participação foi voluntária, o formulário não foi identificado pelo nome para que fosse mantido o anonimato dos participantes e continha poucas perguntas evitando assim o cansaço e estresse ao respondêlo.

Como benefícios, os participantes receberam uma breve explicação/orientação sobre a importância do cuidado em saúde bucal, a fim de evitar o aparecimento de lesões de cárie e consequentemente restaurações invasivas.

\subsection{Análise estatística}

O teste não paramétrico de Qui-quadrado foi utilizado para estimar a associação entre as diferentes categorias dos dados. Em todo o estudo, estipulou-se o nível de significância em 5\%, sendo as análises realizadas por meio do software Bioestat versão 5.3. O software online Word Cloud Generator - Jason Davies foi utilizado para gerar as nuvens de palavras, criadas para a descrição dos resultados qualitativos, esse método se refere a uma lista visualmente hierarquizada na qual serão 
apresentados em destaque os termos mais citados nas respostas dos entrevistados, onde o tamanho de cada palavra indica sua frequência, admitida como proxy da relevância do tema.

\section{Resultados}

A amostra contou com a participação de 200 voluntários, sendo 100 pais ou responsáveis e 100 crianças com idade entre 4 e 10 anos, compondo a amostra, portanto, dois grupos $(n=100)$. Os participantes foram classificados de acordo com sua classe econômica, sendo a maioria dos integrantes representantes das classes C e D. A pergunta aberta sobre o motivo da escolha foi categorizada em grupos, a fim de facilitar a análise dos dados qualitativos de uma forma quantitativa. A caracterização da amostra e a frequência das respostas encontradas durante as entrevistas estão descritas nas tabelas a seguir (Tabelas 1 e 2 ).

Tabela 1 - Frequência das classes dos parâmetros analisados no questionário aplicado aos pais/responsáveis.

\begin{tabular}{|c|c|c|}
\hline $\begin{array}{l}\text { Descrição dos parâmetros analisados } \\
\text { questionário aplicado aos pais/responsáveis }\end{array}$ & Classes dos parâmetros analisados & Frequência \% (n) \\
\hline \multirow{2}{*}{ Gênero } & Masculino & $18(18,0)$ \\
\hline & Feminino & $82(82,0)$ \\
\hline \multirow{3}{*}{ Idade } & Até 30 anos & $21(21,0)$ \\
\hline & 31 a 40 anos & $47(47,0)$ \\
\hline & Acima de 40 anos & $32(32,0)$ \\
\hline \multirow{5}{*}{ Renda } & Classe A & $8(8,0)$ \\
\hline & Classe B & $18(18,0)$ \\
\hline & Classe C & $27(27,0)$ \\
\hline & Classe D & $40(40,0)$ \\
\hline & Classe E & $7(7,0)$ \\
\hline \multirow{3}{*}{$\begin{array}{l}\text { Qual material restaurador mostrado na imagem você } \\
\text { prefere? }\end{array}$} & Amálgama & $0(0,0)$ \\
\hline & Resina composta & $97(97,0)$ \\
\hline & Resina colorida & $3(3,0)$ \\
\hline \multirow{5}{*}{ Qual o motivo da sua escolha? } & Estética & $99(99,0)$ \\
\hline & Gosto por objetos coloridos & $0(0,0)$ \\
\hline & Cor preferida & $1(1,0)$ \\
\hline & Cor de Personagem & $0(0,0)$ \\
\hline & Igual ao do pai & $0(0,0)$ \\
\hline
\end{tabular}

Fonte: Dados da pesquisa (2021). 
Tabela 2 - Frequência das classes dos parâmetros analisados no questionário aplicado às crianças.

\begin{tabular}{|c|c|c|}
\hline $\begin{array}{lcccc}\text { Descrição dos } & \text { parâmetros } & \text { analisados } & \text { no } \\
\text { questionário aplicado as crianças } & & \end{array}$ & Classes dos parâmetros analisados & Frequência \% (n) \\
\hline \multirow{2}{*}{ Gênero } & Masculino & $48(48,0)$ \\
\hline & Feminino & $52(52,0)$ \\
\hline \multirow{3}{*}{ Idade } & Até 4 anos & $11(11,0)$ \\
\hline & 5 a 7 anos & $45(45,0)$ \\
\hline & Acima de 7 anos & $44(44,0)$ \\
\hline \multirow{3}{*}{$\begin{array}{l}\text { Qual material restaurador mostrado na imagem você } \\
\text { prefere? }\end{array}$} & Amálgama & $4(4,0)$ \\
\hline & Resina composta & $34(34,0)$ \\
\hline & Resina colorida & $62(62,0)$ \\
\hline \multirow{5}{*}{ Qual o motivo da sua escolha? } & Estética & $55(55,0)$ \\
\hline & Gosto por objetos coloridos & $9(9,0)$ \\
\hline & Cor preferida & $31(31,0)$ \\
\hline & Cor de Personagem & $4(4,0)$ \\
\hline & Igual ao do pai & $1(1,0)$ \\
\hline
\end{tabular}

Fonte: Dados da pesquisa (2021).

As perguntas foram divididas em 1 (Qual material restaurador mostrado na imagem você prefere?) e pergunta 2 (Qual o motivo da sua escolha?). Foram testadas algumas hipóteses e associações, descritas a seguir:

A) Associação entre a resposta da pergunta 1 das crianças versus pergunta 1 dos pais. Para essa associação não foi observada relação entre as perguntas $(p=0,5705)$. Foi possível observar que a grande maioria os pais $(97 \%)$ estão preocupados com a estética, dessa forma os pais geralmente têm preferência pela resina composta.

B) Associação da idade da criança versus pergunta 1 das crianças. Para essa associação foi observada relação entre a idade da criança e a resposta da pergunta 1 . Crianças menores de 7 anos optam mais por resina colorida se comparado aos outros tipos de material restaurador $(p=0,0130)$.

C) Associação entre renda familiar dos pais versus pergunta 1 dos pais. Não foi observado associação entre renda familiar e a resposta da pergunta 1 dos pais $(p=0,3241)$. A maior parte das famílias foram classificadas como sendo de classe D (40\%) e classe C (27\%). Para classe A temos 8\% das famílias, classes B e E $18 \%$ e $7 \%$ respectivamente.

D) Associação entre renda familiar versus pergunta 1 das crianças. Não foi observado associação entre renda familiar e a resposta da pergunta 1 das crianças $(p=0,1852)$.

E) Associação entre pergunta 1 dos pais versus pergunta 2 dos pais. Em geral, 99\% dos pais optaram pela resina composta como material restaurador, sendo o motivo da escolha relacionado à estética. Não foi possível realizar a estatística de forma confiável, pois não havia variabilidade na amostra.

F) Associação entre pergunta 1 das crianças versus pergunta 2 das crianças. Foi encontrada associação positiva entre as perguntas 1 e 2 respondidas pelos filhos, onde aqueles que optaram pela resina colorida como material restaurador fizeram esta escolha por estar relacionado à cor de algo importante em suas vidas como por exemplo, cor de objetos, personagens ou até mesmo, a cor preferida da criança $(p=0,0001)$.

As respostas da pergunta 2 (Qual o motivo da sua escolha?), foram inseridas no software online Word Cloud Generator - Jason Davies, a fim de gerar uma representação visual dos dados qualitativos obtidos na entrevista. Foi possível 
observar uma maior frequência de palavras relacionadas ao aspecto estético das restaurações na nuvem de palavras das respostas da pergunta 2 dos pais, conforme a figura a seguir (Figura 1).

Figura 1 - Nuvem de palavras representando as respostas da pergunta 2 dos pais.

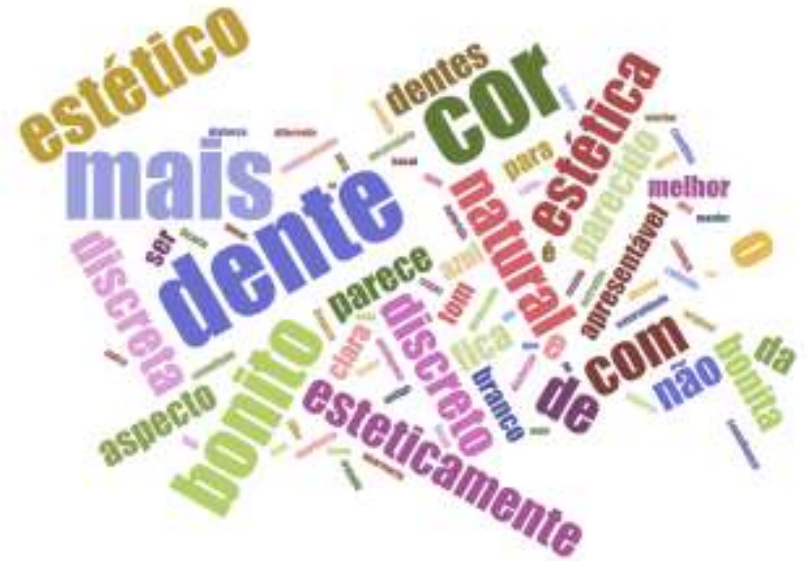

Fonte: Autores (2021).

Já na representação visual das respostas da pergunta 2 das crianças foi possível observar um maior número de palavras e expressões relacionadas à escolha pelo gosto da cor, afinidade com objetos ou personagens que possuem a mesma cor das restaurações apresentadas nas imagens no momento da entrevista, conforme ilustrado na figura a seguir (Figura 2).

Figura 2 - Nuvem de palavras representando as respostas da pergunta 2 das crianças.

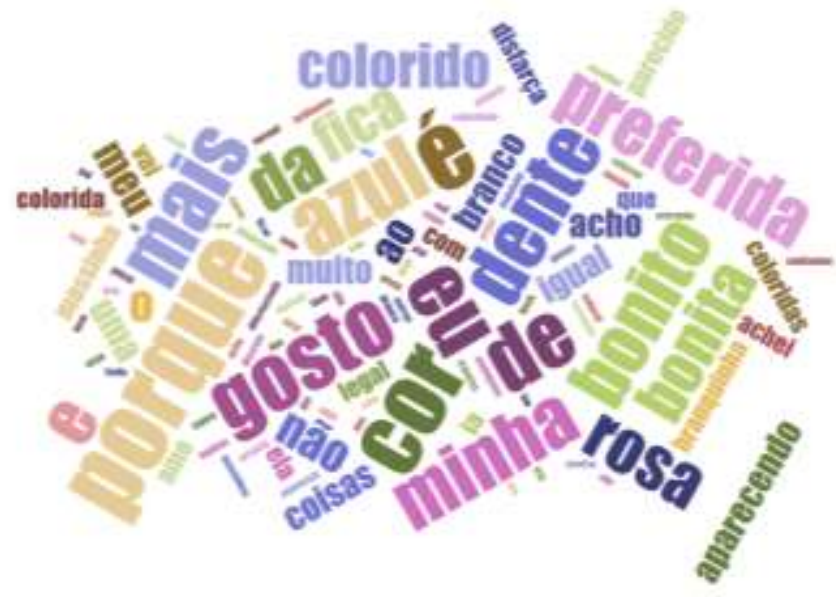

Fonte: Autores (2021).

\section{Discussão}

A cárie dentária, definida como uma doença crônica, multifatorial e dieta dependente, é considerada uma das desordens bucais mais comuns entre as crianças de todo o mundo, afetando cerca de 60 a $90 \%$ dessa população (Petersen, Bourgeois, Ogawa, Estupinan-Day \& Ndiaye, 2005, Hugar et al., 2017). Pesquisas indicam que no Brasil, crianças de até 5 anos de idade manifestam aproximadamente 2,43 dentes com experiência de cárie, semelhantemente $43,5 \%$ das crianças brasileiras até os 12 anos de idade apresentam a doença na dentição permanente (Brasil, 2012). Logo, infere-se que independente dos grandes avanços na área, como a odontologia minimamente invasiva e acessibilidade a programas preventivos de saúde bucal, o índice desta doença em crianças ainda é alto, e este fato pode ser atribuído ao medo relacionado 
ao tratamento odontológico, à baixa adesão aos hábitos de higiene bucal, e a dificuldade de motivação dos pacientes infantis em receber algum procedimento dentário (Hugar et al., 2017).

Sabendo-se que o método mais utilizado nos dias atuais para abordar as lesões cariosas é o tratamento invasivo, que envolve o uso de brocas rotativas e instrumentos manuais para remoção da dentina cariada e, em seguida, preenchimento da cavidade com um material restaurador, compreende-se que, ter bons materiais restauradores, com boas propriedades, e que satisfaçam a questão lúdica, é um benefício em odontopediatria, pois conciliar um tratamento de qualidade, a motivação e a colaboração do paciente infantil frente aos procedimentos odontológicos se configura como um dos requisitos para diminuir a alta prevalência da doença cárie, bem como sua recidiva (Dorri et al., 2015, Souza et al., 2020).

Em relação aos materiais dentários, os mais indicados para restaurações de lesões cariosas cavitadas são aqueles que, dentre várias propriedades, possuem boa resistência mecânica à mastigação, custo benefício favorável e, de preferência, os que proporcionem remineralização por meio do flúor. Ademais, além dessas propriedades a odontologia infantil exige um material restaurador de rápida e fácil aplicação, com boas propriedades adesivas, longevidade clínica e bons resultados estéticos (Berg, 1998, Santos et al., 2020).

Desse modo, alguns dos materiais restauradores utilizados em odontopediatria são amálgama, cimento de ionômero de vidro, resina composta e os compômeros, sendo sua mais nova forma de apresentação (em cores) o atrativo que vem popularizando seu uso nessa área infantil.

Segundo Giuriato (2014) e Martins (2014) a palavra estética significa sensação/percepção da beleza, e esta é considerada subjetiva, ou seja, uma qualidade que depende puramente dos gostos do indivíduo que contempla o objeto em si. Semelhantemente, quando se refere a estética dentária, especificamente aos materiais restauradores, a percepção do que é belo ou não, é transversal e varia conforme os gostos, a idade, os valores pessoais e as classes socioeconômicas.

Estética do ponto de vista adulto, é algo que se enquadra dentro do padrão estabelecido pela sociedade, logo, a coloração dental é considerada estética quando se trata de dentes "brancos", o que se traduz nos resultados desta pesquisa que obteve um percentual de $97 \%$ dos pais optando pela resina composta e apresentando como principal motivo de escolha a questão estética e como citado por alguns respondentes "A cor natural dos dentes, branca, traz um aspecto de limpeza". Logo, esses resultados corroboram com os estudos de Crystal et al. (2017), que afirmaram que a "aceitação pelos pais de qualquer nova técnica ou material restaurador, leva em conta a estética como preocupação primordial”. De igual semelhança El Mourad et al. (2021) afirmaram em seu estudo sobre a autopercepção da estética dentária entre estudantes de odontologia, que a sociedade moderna, por meio da mídia, enfatiza os dentes extremamente brancos como atraentes e aspiracionais para a maioria das pessoas e, consequentemente, a demanda crescente por esse aspecto dentário.

Em contrapartida, a percepção estética das crianças, mostrou-se diferente dos pais, pois $62 \%$ dos participantes do público infantil optaram pela resina/compômero colorido, apresentando como argumento para o motivo da sua escolha a estética por considerarem, do ponto de vista infantil, bonitas as restaurações coloridas, ou ainda justificando a escolha por ser a cor preferida, por ser a cor de algum personagem ou pelo gosto por objetos que possuíssem a mesma cor que a as restaurações coloridas mostradas nas imagens. Ademais, houve uma associação entre a idade da criança e a resposta da pergunta 1, que corresponde ao seu material restaurador preferido, pois a maioria das crianças que optaram pela resina colorida, apresentavam idade entre 4 e 7 anos, esta associação ressalta ainda que crianças mais velhas apresentam percepção estética próxima a do adulto.

Logo, foi possível observar que devido à subjetividade, o conceito percepção estética pode ser diferente no que se refere à visão infantil, principalmente quando envolve crianças em idade pré-escolar, visto que elas possuem visões distintas sobre o que é "feio" ou "bonito", corroborando também com a definição de Giuriato (2014) e Martins (2014) no que diz 
respeito aos quesitos que influenciam essa percepção, destacando-se nessa associação os fatores idade e gostos individuais de quem contempla o objeto.

Em relação ao fator socioeconômico, não houve diferenças estatisticamente significantes entre os grupos de pais pertencentes a diferentes classes sociais, visto que, como citado anteriormente $97 \%$ optaram maioritariamente pela resina composta na cor natural dos dentes, e apenas 3\% dos pais/responsáveis optaram pelo compômero colorido, apresentando como motivo da escolha, a aparência diferente do material, e por acreditarem que seus filhos iriam preferir aquela cor específica. Os respondentes que optaram pelo material colorido, apesar da baixa porcentagem, pertenciam exclusivamente a classes mais baixas como $\mathrm{D}$ e E, porém, não foi possível observar associação entre renda familiar e a resposta da pergunta 1 dos pais pois a maior parte das famílias foram classificadas como sendo de classe D (40\%) e classe C (27\%). Logo, esses resultados sugerem que o nível socioeconômico de uma pessoa não influencia na sua percepção estética.

Já o amálgama de prata, foi rejeitado por $100 \%$ dos pais/responsáveis, sendo alegado que este não é esteticamente bonito e já se tornou ultrapassado, o que confirma a ideia de Iftikhar et al. (2021) que mencionam em seu trabalho a demanda cada vez mais alta dos pacientes em relação a restaurações mais estéticas, e o desuso do amálgama de prata que está sendo menos aceito diante de todas as suas desvantagens, em especial devido ao seu aspecto acinzentado, o que o torna desagradável para a maioria das pessoas.

Apesar de o amálgama de prata não ser bem aceito devido a sua aparência, 4\% das crianças surpreendentemente optaram por este material, justificando-se pelo fato de os pais apresentarem restaurações como essas, e por ser algo diferente. Ainda que essa opção tenha sido escolhida por uma baixa porcentagem de crianças, esse resultado evidencia, mesmo que de forma excepcional, o exemplo dos pais nas escolhas dos seus filhos e a percepção de estética mais uma vez sendo subjetiva, e dependente dos olhos de quem a vê.

Por fim, com a realização dessa pesquisa pôde-se perceber nitidamente a diferença entre as opiniões das crianças e seus respectivos pais/responsáveis em relação aos compômeros coloridos, pois enquanto as crianças a veem como algo bonito, diferente, relacionado a fantasias, sentimentos e personagens infantis, a maioria dos pais rejeitam a ideia e a possibilidade de colocarem um material colorido nos dentes de seus filhos, o vendo não como algo positivo para a facilitação do atendimento e motivação da criança, mas sim como algo ilusório e principalmente com a estética deficiente, o tornando uma opção inviável na escolha do material para o tratamento restaurador.

No entanto, sabendo-se que o comportamento infantil no consultório odontológico muitas vezes é desafiador, e diante dos resultados das crianças em idade pré-escolar que mostraram grande aceitação pelo material colorido, os compômeros seriam uma boa opção, visto que devido à sua apresentação em cores o tornaria mais interessante para a realização de tratamentos em crianças se comparado ao tradicional sistema de sombreamento das resinas. Tal ideia é comprovada nos estudos de Croll, Helpin e Donly (2004) que evidenciam que a possibilidade de escolha de cor, levaria a criança a desenvolver a parte lúdica e transpô-la às manobras clínicas, além disso esse material incentivaria a melhora da higiene bucal da criança, pois esta, estando satisfeita com o material restaurador colorido, associaria uma correta escovação à maior durabilidade da restauração tornando-se, portanto, uma excelente ferramenta motivacional para o tratamento odontológico do público infantil (Santos et al., 2020, Khodadadi et al., 2016).

Ademais, V. Arora, P. Arora, Srivastava e Togoo (2014), em sua revisão sobre o assunto, apontaram, com base em outros estudos, algumas vantagens do uso desse material em odontopediatria, dentre elas, dar às crianças maior sensação de controle e mais envolvimento no tratamento, tornando-o algo divertido, menos assustador e reduzindo a ansiedade dos pequenos e, com isso, espera-se maior colaboração e aceitação da criança frente ao tratamento. No presente estudo, apesar de não mencionadas, estas vantagens não foram reconhecidas pelos pais no momento da entrevista, que priorizaram 
essencialmente a estética dentária, não pensando na possibilidade de que os materiais coloridos trariam um benefício para o tratamento dentário de seus filhos.

No que diz respeito a associação entre pergunta 1 das crianças versus pergunta 2 das crianças, foi encontrada associação positiva entre as duas respostas pois aqueles que optaram pela resina colorida como material restaurador fizeram esta escolha por estar relacionado à cor de algo importante em suas vidas, e isso pode ser explicado pela premissa apresentada pelo filósofo Freud que defende a ideia de que o pensamento infantil "é na verdade uma adaptação do inconsciente à realidade, na forma de desenvolvimento de um ego", ou seja, as crianças, com seu desenvolvimento natural egocêntrico e vivendo em uma realidade utópica preferem escolher as coisas que gostam, sejam elas roupas, desenhos, ou a cor da sua restauração (Maciel, Martins, Pascual \& Maia, 2016).

Desta forma, se há alguma influência positiva do uso de compósitos coloridos para restaurações de lesões de cárie ou aplicação de selantes, quando comparada aos materiais convencionais com relação ao sucesso clínico e adesão ao tratamento infantil, é de extrema importância que os dentistas pediátricos as compreendam e implementem essa nova técnica de condicionamento, atenuando o medo e despertando o interesse da criança em colaborar com a saúde bucal (Maciel et al., 2016, Hugar et al., 2018).

Diante dos resultados apresentados, como a maioria dos pais procura por algo mais estético, e rejeitaram a ideia do material colorido, além da implementação pelo cirurgião-dentista dessa nova técnica de condicionamento, faz-se necessário salientar aos responsáveis a importância da contribuição que os compômeros coloridos podem gerar em casos de pacientes pouco colaboradores e que demandam maior cuidado no que diz respeito ao medo frente ao tratamento odontológico.

Por fim, enfatiza-se que esta pesquisa avaliou somente a questão da percepção estética, sendo que, os custos dos materiais apresentados ou outras questões que poderiam influenciar na escolha dos pais, não foram levados em consideração, logo se esses aspectos fossem considerados, presumivelmente os resultados poderiam ser diferentes, principalmente a associação entre classe social e a pergunta 1 da pesquisa.

\section{Conclusão}

De acordo com os resultados encontrados, apesar da grande aceitação por parte das crianças em relação ao compômero colorido, a maioria dos pais rejeitaram a ideia por priorizarem a estética e a considerarem algo fundamental na escolha de um material restaurador. Porém, sabendo-se que esse material foi aceito positivamente pelas crianças e que este pode atuar como reforço positivo no manejo comportamental, os compósitos coloridos tornam-se uma opção de escolha para os dentistas odontopediátricos no seu dia a dia clínico. No entanto, mais estudos são necessários para consolidar a ideia de que os compômeros coloridos são favoráveis para o tratamento odontopediátrico.

\section{Referências}

American Academy of Pediatric Dentistry (2020). Pediatric restorative dentistry. The Reference Manual of Pediatric Dentistry. 371-383.

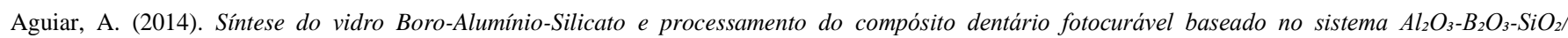
BisGMA/TegDMA/DMAEMA/Canforoquinona (Dissertação de Mestrado). Universidade Federal de Itajubá, Itajubá, MG.

Arinelli, A. M. D., Pereira, K. F., Prado, N. A. S., \& Rabello, T. B. (2016). Sistemas adesivos atuais. Revista Brasileira de Odontologia, $73(3), 242$.

Arora, V., Arora, P., Srivastava, N., \& Togoo, R. A. (2014). Multicoloured restorations for pediatric dental patients. Br J Appl Sci Technol, 4(28), 4014-4025.

Berg, J. H. (1998). The continuum of restorative materials in pediatric dentistry-a review for the clinician. Pediatric Dentistry, 20, 93-100.

Bowen, R. L. (1962). Dental filling material comprising vinyl silane treated fused silica and a binder consisting of the reaction product of bis phenol and glycidyl acrylate. Patent No. 3,066,112.

Brasil, S. B. (2012). Pesquisa Nacional de Saúde Bucal: resultados principais/Ministério da Saúde. Secretaria de Atenção à Saúde. Secretaria de Vigilância em Saúde. Brasília: Ministério da Saúde. 
Bussadori, S. K., Imparato, J. C. P., \& Guedes-Pinto, A. C. (2000). Dentística odontopediátrica: técnicas de trabalho e uso de materiais dentários. Santos.

Correia, A., Oliveira, M. A., \& Silva, M. J. (2005). Conceitos de estratificação nas restaurações de dentes anteriores com resinas compostas. Rev Portug Estomatol, 46(3), 171-178.

Croll, T.P., Helpin, M.L., \& Donly, K.J. (2004). Compômero de cura dupla multicolorido. Odontologia pediátrica, 26 (3), $273-276$.

Crystal, Y.O., Janal, M.N., Hamilton, D.S., \& Niederman, R. (2017). Percepções dos pais e aceitação da coloração com fluoreto de diamina de prata. The Journal of the American Dental Association, 148 (7), 510-518.

Dorri, M., Dunne, S. M., Walsh, T., \& Schwendicke, F. (2015). Micro-invasive interventions for managing proximal dental decay in primary and permanent teeth. Cochrane Database of Systematic Reviews, (11). https://doi.org/10.1002/14651858.CD010431.pub2.

Furtado, G. E. D. S., Sousa, M. D. L. R. D., Barbosa, T. D. S., Wada, R. S., Martínez-Mier, E. D. L. A., \& Almeida, M. E. L. D. (2012). Percepção da fluorose dentária e avaliação da concordância entre pais e filhos: validação de um instrumento. Cadernos de Saúde Pública, 28, $1493-1505$.

Giuriato, J. B. (2014). Estética em odontologia: percepções de acadêmicos de odontologia e pacientes (Dissertação de Mestrado). Universidade de São Paulo, São Paulo, SP. doi:10.11606/D.23.2014.tde-11072014-153726.

Hebling, J., Araújo, F. B.; \& Myaki, S. I. (2017). Dentística Restauradora em Odontopediatria. In: M. D. L. D. A, Massara, \& P. C. B. Rédua (Org.). Manual de referência para procedimentos clínicos em Odontopediatria, (2. ed., cap.15, pp.126-135). Santos, SP: Grupo GEN.

Hugar, S. M., Kohli, D., Badakar, C. M., Gokhale, N. S., Thakkar, P. J. ... Mundada, M. V. (2018). An In Vivo Comparative Evaluation of Dental Anxiety Level and Clinical Success Rate of Composite and Multicolored Compomers in 6 to 12 years of Children. International journal of clinical pediatric dentistry, 11(6), 483-489.

Hugar, S. M., Kohli, D., Badakar, C. M., Vyavahare, S. S., Shah, P. P., Gokhale, N. S., ... Mundada, M. V. (2017). Comparative Assessment of Conventional Composites and Coloured Compomers in Permanent Molars of Children with Mixed Dentition: A Pilot Study. Journal of clinical and diagnostic research: JCDR, 11(6), ZC69-ZC72.

Iftikhar, S., Jahanzeb, N., Saleem, M., Ur Rehman, S., Matinlinna, J. P., \& Khan, A. S. (2021). The trends of dental biomaterials research and future directions: A mapping review. The Saudi dental journal, 33(5), 229-238.

Khodadadi, E., Khafri, S., \& Aziznezhad, M. (2016). Comparison of Surface Hardness of Various Shades of Twinky Star Colored Compomer Light-cured with QTH and LED Units. Electronic physician, 8(5), 2355-2360. https://doi.org/10.19082/2355.

Lima, J. E. D. O. (2007). Cárie dentária: um novo conceito. Revista Dental Press de Ortodontia e Ortopedia Facial, 12, 119-130.

Maciel, M. R., Martins, K. P. H., Pascual, J. G., \& Maia, O. N. (2016). La infancia en Piaget y el infantil en Freud: temporalidad y moralidades. Psicologia Escolar e Educacional, 20, 329-338.

Martins, M. M. G. (2014). Avaliação das perspetivas dos estudantes de Medicina Dentária e dos pacientes quanto à arquitetura dentária e aspeto do sorriso (Dissertação de Mestrado), Universidade Fernando Pessoa, Porto, Portugal.

El Mourad, A. M., Al Shamrani, A., Al Mohaimeed, M., Al Sougi, S., Al Ghanem, S., \& Al Manie, W. (2021). Self-Perception of Dental Esthetics among Dental Students at King Saud University and Their Desired Treatment. International Journal of Dentistry, 2021.

Moreno, V. B., Ribeiro, M., \& Melo, A. T. (2000). Compômero: principais propriedades e indicações. Revista Biociências, 6(2), 49-54.

Petersen, P. E., Bourgeois, D., Ogawa, H., Estupinan-Day, S., \& Ndiaye, C. (2005). The global burden of oral diseases and risks to oral health. Bulletin of the World Health Organization, 83(9), 661-669.

Piva, F., Ribeiro, C. S., \& Coelho-de-Souza, F. H. (2014). Avaliação clínica de restaurações de resina composta em molares decíduos-estudo piloto. Revista da Associacao Paulista de Cirurgioes Dentistas, 68(1), 69-74.

Rosa, N. M. (2018). Amálgama dental, passado ou realidade? (Trabalho de Conclusão de Curso- Graduação). Universidade do Sul de Santa Catarina, Tubarão, SC.

Santos, F. C. P., Santos, S. C. P., Souza, T. R., Paiva, J. C. M., \& Marangoni, A. F. (2020). 10. Percepção do paciente infantil com relação ao uso de materiais restauradores coloridos como fator motivacional no tratamento odontopediátrico em uma clínica-escola. Revista Científica UMC, 5(2).

Silva, A. C. D. (2015). Facetas Cerâmicas. (Trabalho de Conclusão de Curso-Graduação). Universidade Federal de Santa Catarina, Florianópolis, SC.

Souza, L., Nogueira, F., Martins, L., Ferreira, D., Oliveira, F., \& Castro, A. (2020). Behavior and reaction of children to dental care, when submitted to play workshops before and after treatment. RGO-Revista Gaúcha de Odontologia, 68. 